\title{
Prevalence of Metabolic Acidosis Among Patients with Chronic Kidney Disease and Hyperkalemia
}

\author{
Erin E. Cook · Jill Davis · Rubeen Israni · Fan Mu · Keith A. Betts • \\ Deborah Anzalone · Lei Yin · Harold Szerlip • Gabriel I. Uwaifo • \\ Vivian Fonseca · Eric Q. Wu
}

Received: June 29, 2021 / Accepted: August 2, 2021 / Published online: September 1, 2021

(C) The Author(s) 2021

\begin{abstract}
Introduction: Although hyperkalemia and metabolic acidosis often co-occur in patients with chronic kidney disease (CKD), the prevalence of metabolic acidosis among patients with CKD and hyperkalemia is understudied. Therefore, we used medical record data from the Research Action for Health Network to estimate this prevalence.

Methods: Adult patients with CKD stage $3-5, \geq 1$ outpatient potassium value $>5.0 \mathrm{mEq} / \mathrm{l}$, and $\geq 1$ outpatient bicarbonate value available
\end{abstract}

E. E. Cook $(\varangle) \cdot$ F. Mu $\cdot$ E. Q. Wu Analysis Group, Boston, MA, USA e-mail: Erin.Cook@analysisgroup.com

J. Davis · R. Israni · D. Anzalone

AstraZeneca at the Time the Study was Conducted, Wilmington, DE, USA

K. A. Betts · L. Yin

Analysis Group, Los Angeles, CA, USA

H. Szerlip

Baylor University Medical Center, Dallas, TX, USA

G. I. Uwaifo

Ochsner Medical Center, New Orleans, LA, USA

V. Fonseca

Tulane University Medical Center, New Orleans, LA, USA were identified. Patients with end stage kidney disease (ESKD) in the prior year were excluded. The prevalence of metabolic acidosis in each calendar year from 2014 to 2017 among patients with CKD and hyperkalemia was estimated using two definitions of hyperkalemia (potassium $>5.0 \mathrm{mEq} / \mathrm{l}$ and $>5.5 \mathrm{mEq} / \mathrm{l}$ ) and metabolic acidosis (bicarbonate $<18 \mathrm{mEq} / \mathrm{l}$ and $<22 \mathrm{mEq} / \mathrm{l})$.

Results: In the 2017 patient cohort and among patients with CKD and hyperkalemia, patients with metabolic acidosis were younger (69 versus 74 years), more likely to have advanced CKD (35\% versus $13 \%$ ), and use oral sodium bicarbonate (21\% versus $4 \%)$ than patients without metabolic acidosis. The prevalence of metabolic acidosis $(<22 \mathrm{mEq} / \mathrm{l})$ ranged from 25 to $29 \%$ when hyperkalemia was defined by potassium $>5.0 \mathrm{mEq} / \mathrm{l}$ and ranged from 33 to $39 \%$ when hyperkalemia was defined by potassium $>5.5 \mathrm{mEq} / \mathrm{l}$.

Conclusion: Results demonstrated that prevalence estimates of metabolic acidosis varied based on the definition of hyperkalemia and metabolic acidosis utilized.

Keywords: Chronic kidney disease; Hyperkalemia; Metabolic acidosis; Prevalence; Electronic medical records 


\section{Key Summary Points}

Why carry out this study?

Despite the co-occurrence of hyperkalemia and metabolic acidosis among patients with chronic kidney disease (CKD), the prevalence of metabolic acidosis has not been established among patients with these conditions.

This study used electronic medical record data from a large, real-world patient population to estimate the prevalence of metabolic acidosis among patients with CKD and hyperkalemia in the US.

\section{What was learned from the study?}

The prevalence of metabolic acidosis $(<22$ $\mathrm{mEq} / \mathrm{l}$ ) among patients with CKD and hyperkalemia was not uncommon and ranged from 25 to $29 \%$ when

hyperkalemia was defined by potassium $>5.0 \mathrm{mEq} / \mathrm{l}$ and ranged from 33 to $39 \%$ when hyperkalemia was defined by potassium $>5.5 \mathrm{mEq} / \mathrm{l}$ from 2014 to 2017 .

Further research into the management of metabolic acidosis and hyperkalemia with novel treatments would help inform providers and optimize treatment options for these commonly co-occurring conditions, especially among patients with CKD.

\section{INTRODUCTION}

Metabolic acidosis is an acid-base disorder that is a widely recognized complication associated with kidney impairments, particularly CKD $[1,2]$. Due to the lack of overt symptoms during the initial stages of the disorder, metabolic acidosis is often identified based on laboratory assessments of serum bicarbonate levels that are persistently $<22 \mathrm{mEq} / \mathrm{l}$ [3]. The accumulation of excess acid in the body caused by metabolic acidosis can result in the deterioration of bone, loss of muscle, and progression of kidney disease $[2,4,5]$. The prevalence of metabolic acidosis has been reported to range from 2 to $13 \%$ in patients with stage 3 CKD and 19 to $37 \%$ in patients with stage 4 CKD $[2,6]$. The causes of metabolic acidosis vary and include kidney failure, bicarbonate loss, administration of acids, and hyperkalemia [7]. Hyperkalemia, defined as abnormally high serum potassium levels (> $5.0 \mathrm{mEq} / \mathrm{l})$, is common in patients with $\mathrm{CKD}$, and its prevalence increases with $\mathrm{CKD}$ severity (5\% in stage 3 CKD; $43 \%$ in patients on dialysis) $[8,9]$. Severe forms of hyperkalemia $(>6.0 \mathrm{mEq} / \mathrm{l})$ can result in cardiac arrhythmias or sudden death $[10,11]$.

In patients with CKD, hyperkalemia and metabolic acidosis often co-occur as hyperkalemia may cause and be caused by metabolic acidosis [6, 12-15]. Hyperkalemia is thought to cause metabolic acidosis through its impact on kidney ammonia metabolism, such as decreasing ammonia excretion, which can lead to reduced acid excretion [12]. Metabolic acidosis can lead to hyperkalemia through the intracellular to extracellular movement of potassium in exchange for excess hydrogen [13]. As a result, the interrelationship of hyperkalemia and metabolic acidosis is complex and may form a vicious cycle.

Previous studies have reported that metabolic acidosis is not only a known complication of CKD, but also a contributing factor to additional kidney impairments and is associated with rapidity of disease progression $[2,16]$. Treatment of metabolic acidosis has been found to reduce the extent of acidosis and delay CKD progression [17-21]. The clinical management of metabolic acidosis includes reducing acid via dietary changes (e.g., reducing animal-sourced proteins, increasing base-producing fruits and vegetables), the use of loop diuretics, and/or supplementation with sodium-based alkali therapies (e.g., sodium bicarbonate, sodium citrate) $[18,22]$. However, untreated metabolic acidosis is associated with a substantial increase in morbidity and mortality, even if the extent of acidosis is mild $[22,23]$.

Despite the known clinical burden associated with untreated metabolic acidosis, and its co- 
occurrence with hyperkalemia among patients with CKD, the prevalence of metabolic acidosis among patients with both CKD and hyperkalemia has not been widely studied. To date, studies have focused on patients with CKD only $[4,16,17,23-25]$. In light of the complications associated with metabolic acidosis among patients with CKD and hyperkalemia, there is a need to better understand the prevalence of this acid-base disorder among this patient population. To help address this gap in knowledge, this study assessed the prevalence of metabolic acidosis among patients with both CKD and hyperkalemia in the US. The primary objective of the study was to estimate the prevalence of metabolic acidosis among patients with CKD and hyperkalemia using potassium laboratory values to define hyperkalemia (i.e., $>5.0 \mathrm{mEq} / \mathrm{l}$ or $>5.5 \mathrm{mEq} / \mathrm{l}$ ) and bicarbonate laboratory values to define metabolic acidosis (i.e., $<20 \mathrm{mEq} /$ 1 or $<18 \mathrm{mEq} / \mathrm{l})$. The secondary objectives of the study were to (1) characterize the population of patients with CKD and hyperkalemia with and without metabolic acidosis and (2) to assess how using International Classification of Diseases (ICD) codes to estimate the prevalence of metabolic acidosis among patients with CKD and hyperkalemia affect the prevalence estimates compared to using laboratory values.

\section{METHODS}

\section{Data Source}

This retrospective study used electronic medical record (EMR) data from Tulane Medical Center and Ochsner Health System in Louisiana. The EMR data used in this study (2013-2017) were part of the Research Action for Health Network (REACHnet). REACHnet is one of nine clinical research networks that comprise PCORnet ${ }^{\circledR}$, the National Patient-Centered Outcomes Research Network. Data from REACHnet include patient demographics, vital signs, laboratory test results, prescriptions, procedures, and diagnoses.

\section{Compliance with Ethics Guidelines}

This study was approved by the New England Independent Review Board on June 25, 2018. Additional IRB approval was obtained at participating centers wherever needed. This study was performed in accordance with the Helsinki Declaration of 1964, and its later amendments.

\section{Study Design and Sample Selection}

We selected patient samples for each calendar year from 2014 to 2017 to estimate annual prevalence of metabolic acidosis of each calendar year. We characterized the patient population with and without metabolic acidosis among patients with CKD and hyperkalemia using the patient sample from the most recent calendar year 2017 given the sample sizes and patient characteristics were similar across calendar years.

Adult patients were eligible for inclusion in this study if they met two criteria. The first criterion was a documented diagnosis of CKD stage 3-5 in the previous year, defined as $\geq 2$ estimated glomerular filtration rate (eGFR) values $<60 \mathrm{ml} / \mathrm{min} / 1.73 \mathrm{~m}^{2}$ occurring at least 90 days apart or $\geq 1$ diagnosis code indicating CKD stage 3-5. Patients were excluded if they had end-stage kidney disease (ESKD) in the previous year, which was defined as having both CKD stage 5 and dialysis, since patients who were already on dialysis may have bicarbonate values that no longer reflect their true blood level; however, patients were included if they developed ESKD in the current calendar year. The second criterion was evidence of $\geq 1$ outpatient potassium laboratory value $>5.0 \mathrm{mEq} / \mathrm{l}$ and $\geq 1$ outpatient serum bicarbonate laboratory value available on the same day.

The prevalence of metabolic acidosis among patients with CKD and hyperkalemia was determined based on combinations of the following definitions of hyperkalemia and metabolic acidosis among patients with CKD: (1) serum potassium $>5.0 \mathrm{mEq} / \mathrm{l}$ and serum bicarbonate $<22 \mathrm{mEq} / \mathrm{l}$; (2) serum potassium $>5.0 \mathrm{mEq} / \mathrm{l}$ and serum 
bicarbonate $<18 \mathrm{mEq} / \mathrm{l}$; (3) serum potassium $>5.5 \mathrm{mEq} / \mathrm{l}$ and serum bicarbonate $<22 \mathrm{mEq} / \mathrm{l}$; (4) serum potassium $>5.5 \mathrm{mEq} /$ 1 and serum bicarbonate $<18 \mathrm{mEq} / \mathrm{l}$. As a sensitivity analysis, the prevalence of metabolic acidosis, where metabolic acidosis was identified by ICD diagnosis codes (ICD-9-CM 276.2, ICD-10-CM E87.2), was also assessed among the population of patients with CKD and hyperkalemia in 2017. The ICD code for metabolic acidosis had to be recorded within \pm 1 month of the date of the outpatient serum potassium and bicarbonate laboratories as specified in the inclusion criteria. The buffer of \pm 1 month was chosen since the diagnosis code for metabolic acidosis may not always be recorded on the same day as the laboratory value in the EMR.

\section{Statistical Analyses}

Patient characteristics, comorbidities, hyperkalemia treatments, and laboratory values were described and compared for the sample of patients with CKD and hyperkalemia (potassium $>5.0 \mathrm{mEq} / \mathrm{l}$ ) by metabolic acidosis status (bicarbonate $<22 \mathrm{mEq} / \mathrm{l}$ vs. bicarbonate $\geq 22 \mathrm{mEq} / \mathrm{l}$ ) in 2017 . The potassium and bicarbonate laboratory values were characterized using the first pair of potassium and bicarbonate laboratory values on the same day where the potassium laboratory value indicated hyperkalemia (>5.0 mEq/l). Continuous variables were described using means and standard deviations (SDs) and were compared between patients with and without metabolic acidosis using Wilcoxon rank-sum tests; categorical variables were described using counts and proportions and were compared between patients with and without metabolic acidosis using chisquare tests.

The yearly period prevalence of metabolic acidosis among patients with CKD and hyperkalemia was assessed each year from 2014 to 2017. The prevalence of metabolic acidosis was age and sex standardized to the US population of adults from the US Census Bureau estimated to have CKD and hyperkalemia. The prevalence of hyperkalemia among patients with CKD was derived from the analysis by Betts et al. using data from the IBM MarketScan Commercial, Medical Supplemental, and Lab Databases [8]. Linear regression models were fit to prevalence data from 2014 to 2017 to estimate the $p$-value for the trend in prevalence. $p$ values $<0.05$ were considered statistically significant. The rate of metabolic acidosis was also calculated as the number of metabolic acidosis events per patient-year among patients with CKD and hyperkalemia.

For the sensitivity analysis, the prevalence of metabolic acidosis defined by ICD codes was estimated for 2017 among patients with CKD and hyperkalemia. The concordance of metabolic acidosis ICD codes with metabolic acidosis defined by bicarbonate laboratory values was assessed using sensitivity, specificity, and concordance, where the bicarbonate laboratory result was considered to be the true value. As a result, the sensitivity was the probability of having an ICD code for metabolic acidosis among people without metabolic acidosis defined by the serum bicarbonate laboratory value; the specificity was the probability of not having an ICD code for metabolic acidosis among people without metabolic acidosis defined by the serum bicarbonate laboratory value. The concordance was measured as the percentage of bicarbonate laboratory results and ICD codes in agreement.

\section{RESULTS}

\section{Prevalence and Rate of Metabolic Acidosis from 2014 to 2017}

Patients with CKD and hyperkalemia that had $\geq 1$ bicarbonate laboratory results available on the same day as the potassium laboratory values were identified each year from 2014 to 2017 (Fig. 1). When using serum potassium was $>5.0 \mathrm{mEq} / \mathrm{l}$ to define hyperkalemia, a total of 2534-4506 patients were included in the analysis from 2014 to 2017; when using serum potassium $>5.5 \mathrm{mEq} / \mathrm{l}$ to define hyperkalemia, a total of 698-1195 patients were included in the analysis from 2014 to 2017 . The prevalence of metabolic acidosis from 2014 to 2017 observed in this study, among patients with 


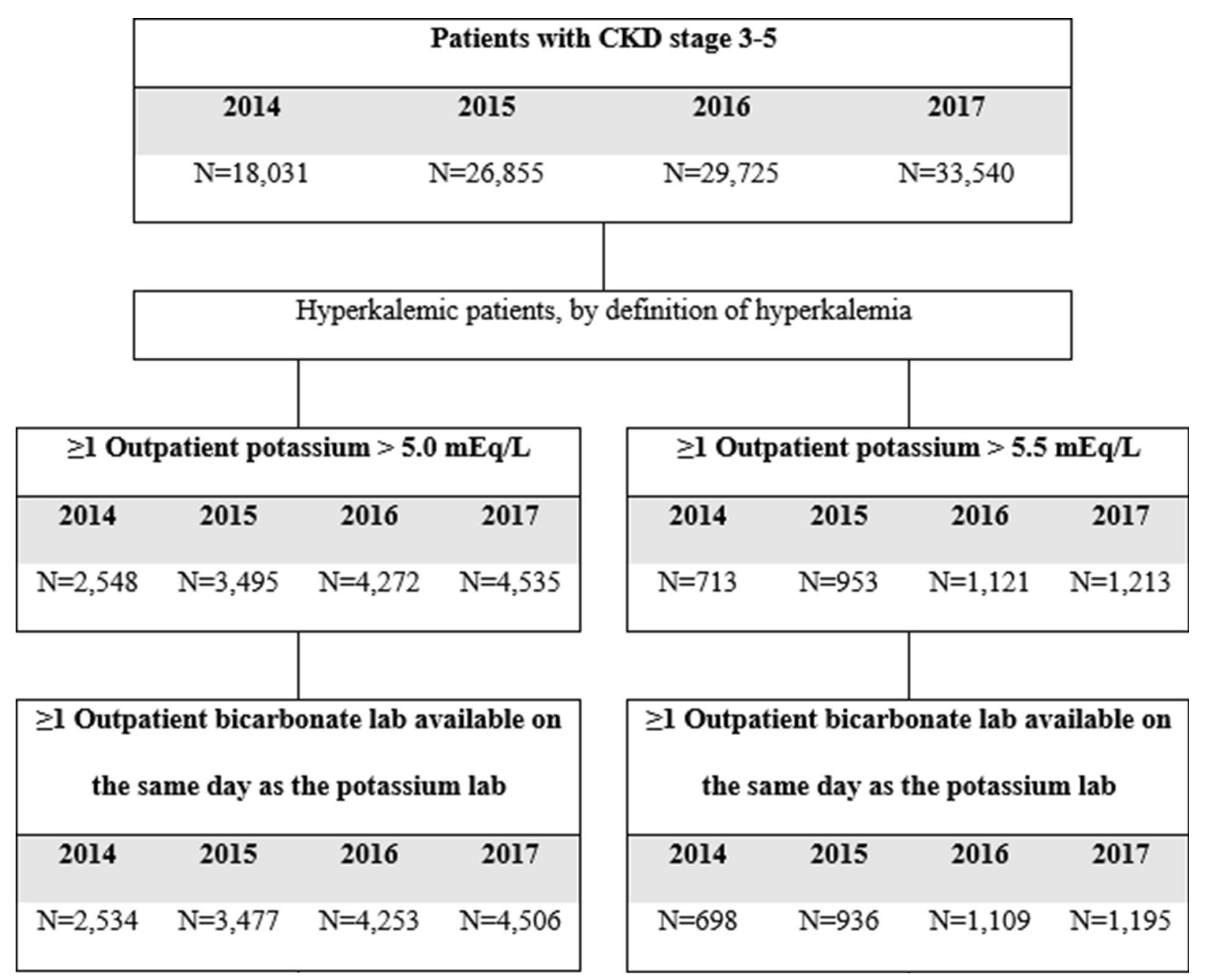

Fig. 1 Yearly samples of patients with CKD and hyperkalemia. CKD chronic kidney disease, $N$ number

CKD and potassium levels $>5.0 \mathrm{mEq} / \mathrm{l}$, ranged from 24.5 to $29.4 \%$ when metabolic acidosis was defined as bicarbonate levels $<22 \mathrm{mEq} / \mathrm{l}$ and ranged from 5.5 to $6.9 \%$ when metabolic acidosis was defined as bicarbonate levels $<18 \mathrm{mEq} / \mathrm{l}$ (Table 1$)$. The rate of metabolic acidosis among patients with CKD and potassium levels $>5.0 \mathrm{mEq} / \mathrm{l}$ ranged from 0.42 per patient-year to 0.52 per patient-year for bicarbonate levels $<22 \mathrm{mEq} / \mathrm{l}$ and ranged from 0.08 per patient-year to 0.11 per patient-year for bicarbonate levels $<18 \mathrm{mEq} / \mathrm{l}$ (Table 1 ).

The prevalence and rate were slightly higher among patients with CKD and potassium levels $>5.5 \mathrm{mEq} / \mathrm{l}$. The prevalence of metabolic acidosis among patients with CKD and potassium $>5.5 \mathrm{mEq} / \mathrm{l}$ ranged from 33.1 to $39.1 \%$ when metabolic acidosis was defined as bicarbonate levels $<22 \mathrm{mEq} / \mathrm{l}$ and ranged from 9.1 to $10.8 \%$ when metabolic acidosis was defined as bicarbonate levels $<18 \mathrm{mEq} / \mathrm{l}$ (Table 1 ). The rate of metabolic acidosis among patients with CKD and potassium levels $>5.5 \mathrm{mEq} / \mathrm{l}$ ranged from 0.46 per patient-year to 0.57 per patientyear for bicarbonate levels $<22 \mathrm{mEq} / \mathrm{l}$ and ranged from 0.12 per patient-year to 0.15 per patient-year for bicarbonate levels $<18 \mathrm{mEq} / \mathrm{l}$ (Table 1).

The observed prevalence of metabolic acidosis in this study was similar to the age and gender standardized prevalence of metabolic acidosis (Fig. 2). The age and gender standardized prevalence of metabolic acidosis among patients with CKD and potassium 
Table 1 Prevalence and rate of metabolic acidosis among patients with CKD and hyperkalemia

\begin{tabular}{|c|c|c|c|c|c|c|}
\hline & \multicolumn{3}{|c|}{$\begin{array}{l}\text { Hyperkalemia } \\
(\text { Potassium > } 5.0 \mathrm{mEq} / \mathrm{l})\end{array}$} & \multicolumn{3}{|c|}{$\begin{array}{l}\text { Hyperkalemia } \\
\text { (Potassium > } 5.5 \mathrm{mEq} / \mathrm{l})\end{array}$} \\
\hline & $\begin{array}{l}\mathrm{N} \text { with metabolic } \\
\text { acidosis }\end{array}$ & $\begin{array}{l}\text { Prevalence } \\
(\%)\end{array}$ & Rate $^{1}$ & $\begin{array}{l}\mathrm{N} \text { with metabolic } \\
\text { acidosis }\end{array}$ & $\begin{array}{l}\text { Prevalence } \\
(\%)\end{array}$ & Rate $^{1}$ \\
\hline \multicolumn{7}{|l|}{2014} \\
\hline Bicarbonate $<22 \mathrm{mEq} / \mathrm{l}$ & 745 & 29.40 & 0.52 & 256 & 36.68 & 0.57 \\
\hline Bicarbonate $<18 \mathrm{mEq} / \mathrm{l}$ & 154 & 6.08 & 0.10 & 67 & 9.60 & 0.13 \\
\hline \multicolumn{7}{|l|}{2015} \\
\hline Bicarbonate $<22 \mathrm{mEq} / \mathrm{l}$ & 989 & 28.44 & 0.51 & 366 & 39.10 & 0.57 \\
\hline Bicarbonate $<18 \mathrm{mEq} / \mathrm{l}$ & 241 & 6.93 & 0.11 & 101 & 10.79 & 0.15 \\
\hline \multicolumn{7}{|l|}{2016} \\
\hline Bicarbonate $<22 \mathrm{mEq} / \mathrm{l}$ & 1143 & 26.88 & 0.47 & 396 & 35.71 & 0.50 \\
\hline Bcarbonate $<18 \mathrm{mEq} / \mathrm{l}$ & 235 & 5.53 & 0.08 & 121 & 9.11 & 0.12 \\
\hline \multicolumn{7}{|l|}{2017} \\
\hline Bicarbonate $<22 \mathrm{mEq} / \mathrm{l}$ & 1104 & 24.50 & 0.42 & 395 & 33.05 & 0.46 \\
\hline Bicarbonate $<18 \mathrm{mEq} / \mathrm{l}$ & 248 & 5.50 & 0.08 & 121 & 10.13 & 0.13 \\
\hline
\end{tabular}

$C K D$ chronic kidney disease, $N$ number

${ }^{1}$ Rates were calculated as the number of metabolic acidosis events per patient-year

levels $>5.0 \mathrm{mEq} / \mathrm{l}$ ranged from 24.3 to $29.3 \%$ when metabolic acidosis was defined as bicarbonate levels $<22 \mathrm{mEq} / \mathrm{l}$ and ranged from 5.4 to $6.7 \%$ when metabolic acidosis was defined as bicarbonate levels $<18 \mathrm{mEq} / \mathrm{l}$. The age and gender standardized prevalence among patients with CKD and potassium levels $>5.5 \mathrm{mEq} / \mathrm{l}$ ranged from 33.9 to $39.3 \%$ for bicarbonate levels $<22 \mathrm{mEq} / \mathrm{l}$ and ranged from 9.0 to $10.8 \%$ for bicarbonate levels $<18 \mathrm{mEq} / \mathrm{l}$. There did not appear to be any strong year-over-year trends in the prevalence of metabolic acidosis among patients with CKD and hyperkalemia.

\section{Prevalence of Metabolic Acidosis Defined by Diagnosis Codes and Concordance with Bicarbonate Laboratory Values}

The prevalence of metabolic acidosis among patients with CKD and potassium $>5.0 \mathrm{mEq} / \mathrm{l}$ was $8.2 \%$ using diagnosis codes for metabolic acidosis, compared to $24.5 \%$ using bicarbonate laboratory values $<22 \mathrm{mEq} / \mathrm{l}$ and $5.5 \%$ using bicarbonate laboratory values $<18 \mathrm{mEq} / \mathrm{l}$ (Table 2). For metabolic acidosis defined as bicarbonate $<22 \mathrm{mEq} / \mathrm{l}$ and among patients with CKD and potassium $>5.0 \mathrm{mEq} / \mathrm{l}$, the concordance was high $(80.0 \%)$. Additionally, the specificity was high $(96.2 \%)$, indicating that few people had an ICD code for metabolic acidosis when their bicarbonate value was $\geq 22 \mathrm{mEq} / \mathrm{l}$. However, the sensitivity was low (21.7\%), indicating that patients with bicarbonate $<22 \mathrm{mEq} / \mathrm{l}$ were not very likely to have an ICD code for metabolic acidosis. For metabolic acidosis defined as bicarbonate $<18 \mathrm{mEq} / \mathrm{l}$ and among patients with CKD and potassium $>5.0 \mathrm{mEq} / \mathrm{l}$, the sensitivity was slightly higher but still low (40.7\%) and the specificity $(93.7 \%)$ and concordance $(90.8 \%)$ remained high.

The prevalence of metabolic acidosis among patients with CKD and potassium $>5.5 \mathrm{mEq} / \mathrm{l}$ was $13.3 \%$ using diagnosis codes for metabolic acidosis compared to $33.1 \%$ using bicarbonate laboratory values $<22 \mathrm{mEq} / \mathrm{l}$ and $10.1 \%$ using 


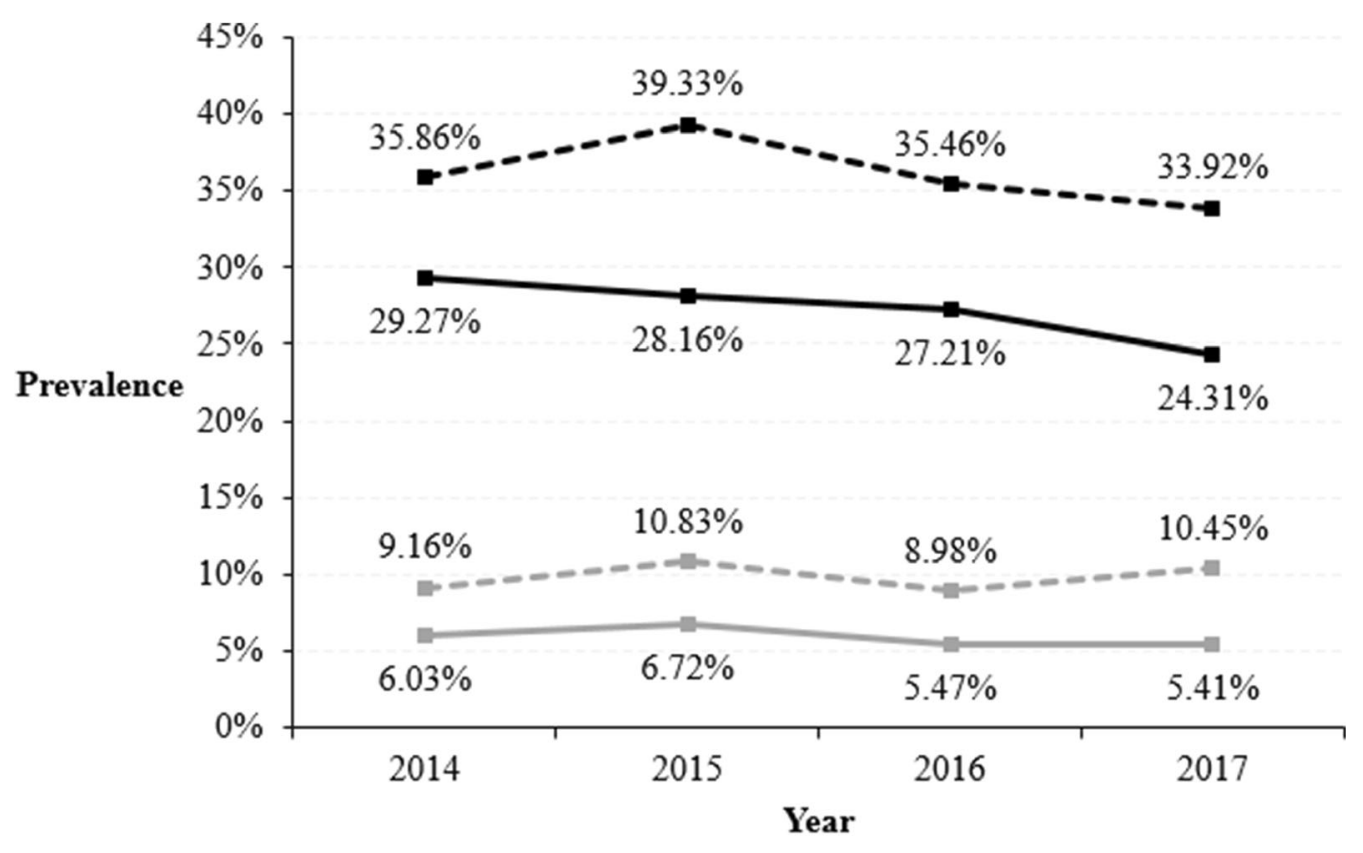

$$
\begin{aligned}
& - \text { Potassium }>5.0 \mathrm{mEq} / \mathrm{L} \text { and Bicarbonate }<22 \mathrm{mEq} / \mathrm{L}, \mathrm{p} \text { for trend }=0.04 \\
& \text { - }- \text { Potassium }>5.5 \mathrm{mEq} / \mathrm{L} \text { and } \text { Bicarbonate }<22 \mathrm{mEq} / \mathrm{L}, \mathrm{p} \text { for trend }=0.45 \\
& - \text { - Potassium }>5.0 \mathrm{mEq} / \mathrm{L} \text { and Bicarbonate }<18 \mathrm{mEq} / \mathrm{L}, p \text { for trend }=0.34 \\
& -- \text { Potassium }>5.5 \mathrm{mEq} / \mathrm{L} \text { and Bicarbonate }<18 \mathrm{mEq} / \mathrm{L}, p \text { for trend }=0.72
\end{aligned}
$$

Fig. 2 Age and gender standardized prevalence of metabolic acidosis among patients with CKD and hyperkalemia. $C K D$ chronic kidney disease

bicarbonate laboratory values $<18 \mathrm{mEq} / \mathrm{l}$ (Table 2). Similar to when hyperkalemia was defined as potassium $>5.0 \mathrm{mEq} / \mathrm{l}$, the sensitivity was low (25.6\%) and specificity (92.8\%) and concordance $(70.5 \%)$ were high for metabolic acidosis defined as bicarbonate $<22 \mathrm{mEq} / \mathrm{l}$. For metabolic acidosis defined as bicarbonate $<18 \mathrm{mEq} / \mathrm{l}$ and among patients with CKD and potassium $>5.5 \mathrm{mEq} / \mathrm{l}$, the sensitivity was slightly higher but still low (38.8\%) and the specificity (89.6\%) and concordance (84.4\%) remained high.

\section{Characteristics of Patients with and Without Metabolic Acidosis (Bicarbonate $<22 \mathrm{mEq} / \mathrm{l}$ )}

In 2017, among patients with CKD and hyperkalemia (potassium $>5.0 \mathrm{mEq} / \mathrm{l}$ ), patients with metabolic acidosis (bicarbonate $<22 \mathrm{mEq} / \mathrm{l}$ ) were younger than patients without metabolic acidosis (68.7 years vs. 74.0 years, respectively, $p<0.001$; Table 3). In both cohorts, most patients were White, although patients with metabolic acidosis were more likely to be Black compared to patients without metabolic acidosis $(41.9 \%$ vs. $25.4 \%$, respectively, $p<0.001)$.

Among patients with CKD and hyperkalemia (potassium $>5.0 \mathrm{mEq} / \mathrm{l}$ ), patients with metabolic acidosis (bicarbonate $<22 \mathrm{mEq} / \mathrm{l}$ ) were more likely to have advanced CKD (stage 5 or ESKD: $34.8 \%$ vs. $13.4 \%$; Table 3). The most common comorbidities in patients with CKD and hyperkalemia with and without metabolic acidosis were hypertension $(96.0 \%$ vs. $93.6 \%$, respectively, $p=0.003)$, type II diabetes $(62.6 \%$ vs. $56.3 \%, p<0.001)$, acute kidney injury ( $45.1 \%$ vs. $23.4 \%, p<0.001)$, and heart failure (35.0\% vs. $31.2 \%, p=0.020)$. The mean Charlson Comorbidity Index $( \pm \mathrm{SD})$ was higher among patients with metabolic acidosis 
Table 2 The 2017 prevalence of metabolic acidosis defined by ICD codes and agreement with metabolic acidosis defined by laboratory values

\begin{tabular}{|c|c|c|c|c|c|}
\hline & $\begin{array}{l}\text { Prevalence of } \\
\text { metabolic acidosis } \\
\text { (bicarbonate labs) }(\%)^{1}\end{array}$ & $\begin{array}{l}\text { Prevalence of } \\
\text { metabolic acidosis } \\
(\text { ICD codes })(\%)^{2}\end{array}$ & $\begin{array}{l}\text { Sensitivity } \\
(\%)^{3}\end{array}$ & $\begin{array}{l}\text { Specificity } \\
(\%)^{4}\end{array}$ & $\begin{array}{l}\text { Concordance } \\
(\%)^{5}\end{array}$ \\
\hline \multicolumn{6}{|c|}{ CKD and hyperkalemia $>5.0 \mathrm{mEq} / 1$} \\
\hline Bicarbonate $<22 \mathrm{mEq} / \mathrm{l}$ & 24.50 & 8.17 & 21.74 & 96.24 & 77.99 \\
\hline Bicarbonate $<18 \mathrm{mEq} / \mathrm{l}$ & 5.50 & 8.17 & 40.73 & 93.73 & 90.81 \\
\hline \multicolumn{6}{|c|}{ CKD and hyperkalemia $>5.5 \mathrm{mEq} / 1$} \\
\hline Bicarbonate $<22 \mathrm{mEq} / \mathrm{l}$ & 33.05 & 13.31 & 25.57 & 92.75 & 70.54 \\
\hline Bicarbonate $<18 \mathrm{mEq} / \mathrm{l}$ & 10.13 & 13.31 & 38.84 & 89.57 & 84.44 \\
\hline
\end{tabular}

CKD chronic kidney disease, ICD International Classification of Disease

${ }^{1}$ All analyses represent the prevalence in 2017

2 ICD codes to identify metabolic acidosis included ICD-9-CM 276.2 and ICD-10-CM E87.2

3 Sensitivity is the probability of having an ICD code for metabolic acidosis among patients with metabolic acidosis defined by the serum bicarbonate laboratory value

${ }^{4}$ Specificity is the probability of not having an ICD code for metabolic acidosis among patients without metabolic acidosis defined by the serum bicarbonate laboratory value

${ }^{5}$ Concordance is the probability of having an ICD code for metabolic acidosis and a serum bicarbonate laboratory value in agreement

compared to patients without metabolic acidosis $(3.8 \pm 2.3$ vs. $3.2 \pm 2.1$, respectively, $p<0.001)$. Over half of all patients in both cohorts used any renin-angiotensin-aldosterone system inhibitors (RAASis), although the percentage of patients with metabolic acidosis using RAASis was slightly lower than the percentage of patients without metabolic acidosis (54.3\% vs. $59.8 \%$, respectively, $p=0.001)$.

Treatments for hyperkalemia were more commonly used among patients with metabolic acidosis compared to patients without metabolic acidosis, including a higher proportion using potassium binders $(31.1 \%$ vs. $10.5 \%$, respectively, $p<0.001)$, diuretics $(61.2 \%$ vs. $52.0 \%, p<0.001)$, and temporizing agents such as albuterol $(21.3 \%$ vs. $16.1 \%, p<0.001)$.

Medications that can be used to treat hyperkalemia and metabolic acidosis, such as sodium bicarbonate and sodium citrate, were not widely used (Table 3 ). Sodium bicarbonate was used more commonly in patients with metabolic acidosis than in patients without metabolic acidosis $(28.0 \%$ vs. $8.1 \%$, respectively, $p<0.001)$. Among patients with metabolic acidosis, oral sodium bicarbonate was more commonly used (20.9\%) than intravenous sodium bicarbonate $(9.9 \%)$. Sodium citrate was infrequently used (patients with metabolic acidosis: $0.7 \%$ vs. patients without metabolic acidosis: $0.2 \%, p=0.035$ ).

When the first pair of potassium and bicarbonate laboratory results on the same day was examined, the mean $( \pm S D)$ potassium laboratory value was slightly higher for patients with metabolic acidosis compared to patients without metabolic acidosis ( $5.4 \pm 0.4$ vs. $5.3 \pm 0.3$, $p<0.001)$. Mean ( \pm SD) serum bicarbonate laboratory value was lower among patients with metabolic acidosis compared to patients without metabolic acidosis $(20.4 \pm 3.0$ vs. $26.1 \pm 2.6, p<0.001$, Table 3). Patients with metabolic acidosis also had a lower mean $( \pm \mathrm{SD})$ eGFR (measured closest to the aforementioned pair of potassium and bicarbonate laboratory results) compared with patients without metabolic acidosis $(29.4 \pm 15.9$ vs. $39.6 \pm 15.7$, respectively, $p<0.001$ ). 
Table 3 Characteristics of patients with CKD and hyperkalemia (potassium $>5.0 \mathrm{mEq} / \mathrm{l}$ ) by metabolic acidosis status (bicarbonate $<22 \mathrm{mEq} / \mathrm{l}$ ) in 2017

\begin{tabular}{|c|c|c|c|}
\hline & $\begin{array}{l}\text { CKD patients with hyperkalemia and } \\
\text { metabolic acidosis }{ }^{1} \\
n=1104\end{array}$ & $\begin{array}{l}\text { CKD patients with hyperkalemia and } \\
\text { without metabolic acidosis }{ }^{1} \\
n=3402\end{array}$ & $p$ Value \\
\hline \multicolumn{4}{|l|}{ Demographics } \\
\hline $\begin{array}{l}\text { Age (years) } \\
\text { mean } \pm S D\end{array}$ & $68.7 \pm 14.9$ & $74.0 \pm 13.0$ & $<0.001$ \\
\hline Female, $n(\%)$ & $519(47.0 \%)$ & $1638(48.1 \%)$ & 0.511 \\
\hline \multicolumn{4}{|l|}{ Race, $n(\%)$} \\
\hline White & $623(56.4 \%)$ & $2486(73.1 \%)$ & $<0.001$ \\
\hline Black & $463(41.9 \%)$ & $864(25.4 \%)$ & $<0.001$ \\
\hline Other or missing & $18(1.6 \%)$ & $52(1.5 \%)$ & 0.812 \\
\hline \multicolumn{4}{|l|}{ Comorbidities } \\
\hline \multicolumn{4}{|l|}{ CKD stage, $n(\%)^{2}$} \\
\hline Stage 3 & $353(32.0 \%)$ & $2,083(61.2 \%)$ & $<0.001$ \\
\hline Stage 4 & $340(30.8 \%)$ & $666(19.6 \%)$ & $<0.001$ \\
\hline $\begin{array}{l}\text { Stage } 5 \text { without } \\
\text { dialysis }\end{array}$ & $101(9.1 \%)$ & $84(2.5 \%)$ & $<0.001$ \\
\hline ESKD & $283(25.6 \%)$ & $371(10.9 \%)$ & $<0.001$ \\
\hline $\begin{array}{l}\text { Missing or not stage } \\
3-5\end{array}$ & $27(2.4 \%)$ & $198(5.8 \%)$ & $<0.001$ \\
\hline $\begin{array}{l}\text { Acute kidney injury, } \\
n(\%)\end{array}$ & $498(45.1 \%)$ & $797(23.4 \%)$ & $<0.001$ \\
\hline $\begin{array}{l}\text { Type II diabetes, } \\
n(\%)\end{array}$ & $691(62.6 \%)$ & $1917(56.3 \%)$ & $<0.001$ \\
\hline Heart failure, $n(\%)$ & $386(35.0 \%)$ & $1061(31.2 \%)$ & 0.020 \\
\hline Hypertension, $n(\%)$ & $1060(96.0 \%)$ & $3184(93.6 \%)$ & 0.003 \\
\hline $\mathrm{CCI}$, mean $\pm \mathrm{SD}$ & $3.8 \pm 2.3$ & $3.2 \pm 2.1$ & $<0.001$ \\
\hline \multicolumn{4}{|c|}{ RAASi utilization, n (\%) } \\
\hline Any RAASi & $600(54.3 \%)$ & $2,036(59.8 \%)$ & 0.001 \\
\hline \multicolumn{4}{|c|}{ Hyperkalemia treatments, $n(\%)$} \\
\hline $\begin{array}{l}\text { Any potassium- } \\
\text { binding treatment }\end{array}$ & $343(31.1 \%)$ & $358(10.5 \%)$ & $<0.001$ \\
\hline Any diuretics & $676(61.2 \%)$ & $1,769(52.0 \%)$ & $<0.001$ \\
\hline \multicolumn{4}{|l|}{ Temporizing agents } \\
\hline Albuterol & $235(21.3 \%)$ & $547(16.1 \%)$ & $<0.001$ \\
\hline
\end{tabular}


Table 3 continued

\begin{tabular}{|c|c|c|c|}
\hline & $\begin{array}{l}\text { CKD patients with hyperkalemia and } \\
\text { metabolic acidosis } \\
n=1104\end{array}$ & $\begin{array}{l}\text { CKD patients with hyperkalemia and } \\
\text { without metabolic acidosis }{ }^{1} \\
n=3402\end{array}$ & $\overline{p \text { Value }}$ \\
\hline Calcium & $197(17.8 \%)$ & $203(6.0 \%)$ & $<0.001$ \\
\hline Insulin with glucose & $212(19.2 \%)$ & $234(6.9 \%)$ & $<0.001$ \\
\hline \multicolumn{4}{|c|}{ Treatments for hyperkalemia and metabolic acidosis, $n$ (\%) } \\
\hline Sodium bicarbonate & $309(28.0 \%)$ & $276(8.1 \%)$ & $<0.001$ \\
\hline IV & $109(9.9 \%)$ & $160(4.7 \%)$ & $<0.001$ \\
\hline Oral & $231(20.9 \%)$ & $135(4.0 \%)$ & $<0.001$ \\
\hline Unknown & $18(1.6 \%)$ & $9(0.3 \%)$ & $<0.001$ \\
\hline Sodium citrate & $8(0.7 \%)$ & $8(0.2 \%)$ & 0.035 \\
\hline \multicolumn{4}{|c|}{$\begin{array}{l}\text { Laboratory values closest to the first bicarbonate and potassium laboratory values }>5.0 \mathrm{mEq} / 1 \text { available, }{ }^{4} \\
\text { mean } \pm \mathrm{SD}\end{array}$} \\
\hline Potassium $(\mathrm{mEq} / \mathrm{l})$ & $5.4 \pm 0.4$ & $5.3 \pm 0.3$ & $<0.001$ \\
\hline $\begin{array}{l}\text { Serum bicarbonate } \\
\qquad(\mathrm{mEq} / \mathrm{l})\end{array}$ & $20.4 \pm 3.0$ & $26.1 \pm 2.6$ & $<0.001$ \\
\hline $\begin{array}{c}\text { E GFR }(\mathrm{ml} / \mathrm{min} / \\
\left.1.73 \mathrm{~m}^{2}\right)^{5}\end{array}$ & $29.4 \pm 15.9$ & $39.6 \pm 15.7$ & $<0.001$ \\
\hline
\end{tabular}

$C C I$ Charlson Comorbidity Index, $C K D$ chronic kidney disease, $e G F R$ estimated glomerular filtration rate, ESKD end-stage kidney disease, $I V$ intravenous, $N$ number, $R A A S i$ renin-angiotensin-aldosterone system inhibitor, $S D$ standard deviation

${ }^{1}$ Patient characteristics in 2017 are included in the table

2 CKD stage in 2017 is reported in the table. The most severe CKD stage observed in 2017 was included as the stage of CKD ( $\geq 1$ eGFR or $\geq 1$ diagnosis code). Missing CKD stage indicates that no data on stage were available in 2017 or that CKD was stages 1 or 2 . CKD stage 3 was defined as a diagnosis code for CKD stage 3 or eGFR $30-59 \mathrm{ml} / \mathrm{min} / 1.73 \mathrm{~m}^{2}$. CKD stage 4 was defined as a diagnosis code for CKD stage 4 or eGFR $15-29 \mathrm{ml} / \mathrm{min} / 1.73 \mathrm{~m}^{2}$. CKD stage 5 was defined as a diagnosis code for CKD stage 5 or eGFR $<15 \mathrm{ml} / \mathrm{min} / 1.73 \mathrm{~m}^{2}$ and no dialysis. ESKD was defined as a diagnosis code for CKD stage 5 or eGFR $<15 \mathrm{ml} / \mathrm{min} / 1.73 \mathrm{~m}^{2}$ and dialysis

3 Potassium-binding treatments include sodium polystyrene sulfonate and patiromer

${ }^{4}$ The potassium and bicarbonate laboratory values were characterized using the first pair of potassium and bicarbonate laboratory values on the same day in 2017 where the potassium laboratory value indicated hyperkalemia $(>5.0 \mathrm{mEq} / \mathrm{l})$

5 eGFR was available for 1102 patients with metabolic acidosis and 3398 patients without metabolic acidosis. The eGFR value closest to the first pair of bicarbonate and potassium laboratory results available in 2017 is included

\section{DISCUSSION}

This real-world retrospective study used a large EMR database to determine the prevalence of metabolic acidosis among patients with CKD and hyperkalemia in the US. In particular, this study evaluated different cutoffs to define hyperkalemia (serum potassium levels $>5.0 \mathrm{mEq} / \mathrm{l} \quad$ vs. $>5.5 \mathrm{mEq} / \mathrm{l}$ ) and metabolic acidosis (bicarbonate levels $<18 \mathrm{mEq} / \mathrm{l}$ vs. $<22 \mathrm{mEq} / \mathrm{l})$. Overall, the results of this study found that metabolic acidosis was common among patients with both $\mathrm{CKD}$ and hyperkalemia and that the prevalence of metabolic acidosis is sensitive to the definition of hyperkalemia and metabolic acidosis used. 
The Kidney Disease Improving Global Outcomes guidelines recommend treatment to keep serum bicarbonate $>22 \mathrm{mEq} / \mathrm{l}$, which the Kidney Disease Outcomes Quality Initiative guidelines agree with; however, in practice physicians may not follow those guidelines closely and choose to treat patients at a lower bicarbonate level and will also often consider variables such as blood pH level $[3,26,27]$. The prevalence of metabolic acidosis in this study defined by serum bicarbonate levels $<22 \mathrm{mEq} / \mathrm{l}$ was much higher than the prevalence defined by ICD codes for patients with CKD and hyperkalemia. However, this finding is expected as only more severe patients may have a diagnosis code for metabolic acidosis in clinical practice. In fact, this study reveals that the prevalence of metabolic acidosis among patients with CKD and hyperkalemia defined by ICD codes was much closer to the prevalence defined by bicarbonate $<18 \mathrm{mEq} / \mathrm{l}$. The difference in prevalence defined by bicarbonate $<22 \mathrm{mEq} / \mathrm{l}$ compared to ICD codes may also arise because providers may be less likely to record a diagnosis of metabolic acidosis in the outpatient setting, and this study only included outpatient bicarbonate laboratory values in the assessment of metabolic acidosis. As a result, we anticipate that the true prevalence of metabolic acidosis is closer to the prevalence estimated by the bicarbonate laboratory values rather than the ICD codes alone. Given ICD codes may not capture metabolic acidosis until the bicarbonate level is much lower than $22 \mathrm{mEq} / \mathrm{l}$, better monitoring and clinical attention using bicarbonate laboratory values could potentially result in better patient management and outcomes.

To the best of our knowledge, the current study is the first to determine the prevalence of metabolic acidosis among adult patients with CKD and hyperkalemia. Although the clinical burden of metabolic acidosis has been widely reported, the most commonly studied patient population has been those with varying stages of CKD [4, 16, 17, 23-25]. Among patients with CKD, $15 \%$ have been reported to have metabolic acidosis with an increase in the prevalence with advancing CKD [1, 28-30]. Results from a 2009 study that assessed the onset of CKD-related metabolic complications in $>1000$ adults with CKD stages 2-5 found that as eGFR declined, the prevalence of metabolic acidosis increased from 2 to $39 \%$ and hyperkalemia increased from 2 to $42 \%$ [31]. As metabolic acidosis is a known complication of CKD that both causes and is caused by hyperkalemia, another known complication of CKD $[2,6,29,32,33]$, it is unsurprising that the prevalence of metabolic acidosis reported in this study is higher than the $15 \%$ that has been reported previously [1] among patients with CKD without hyperkalemia.

In patients with $\mathrm{CKD}$, untreated metabolic acidosis can result in muscle wasting, bone disease, additional kidney impairments and CKD progression, and untreated severe hyperkalemia can result in cardiac arrhythmias or sudden death $[2,10,11,16,29]$. As a result, methods to detect metabolic acidosis and appropriately treat patients with metabolic acidosis and hyperkalemia, both common among CKD patients, are important for healthcare stakeholders. Hyperkalemia, which can cause or result from metabolic acidosis, is a challenging disorder to successfully manage in the long term, particularly moderate to severe forms of the disorder [34]. In addition, due to the role of metabolic acidosis as a causative factor in CKD progression and hyperkalemia, it is important for clinicians to consider all three conditions collectively when managing patients with these conditions.

Sodium bicarbonate treatment is a known treatment for metabolic acidosis and hyperkalemia. Among patients with CKD, treating metabolic acidosis with sodium bicarbonate has been shown to improve acidosis and may potentially decrease the rate of CKD progression $[20,29,35]$. However, sodium bicarbonate treatment is associated with some adverse events, such as the production of carbon dioxide in the gastrointestinal tract resulting in belching and gastric distension [22]. For acute hyperkalemia, sodium bicarbonate is typically not used as a first line treatment due to concerns around its efficacy and safety compared to other treatment options for hyperkalemia $[1,11,36]$. In the present study, $28 \%$ of patients with metabolic acidosis received sodium bicarbonate compared with $8 \%$ of patients without 
evidence of metabolic acidosis. However, we are unable to confirm if sodium bicarbonate was specifically prescribed to treat hyperkalemia, metabolic acidosis, or both in this study as such reasons are not available in the EMR data. Novel treatments for hyperkalemia have been shown to impact bicarbonate levels. In a phase III study, sodium zirconium cyclosilicate has been shown to improve potassium and bicarbonate levels among patients with hyperkalemia [37]. During the 1-year trial period, the proportion of patients with bicarbonate $<22 \mathrm{mEq} / \mathrm{l}$ decreased from $28 \%$ at baseline to $17 \%$ after 1 year [37]. Further research into treatment options' impact on treating both metabolic acidosis and hyperkalemia would help inform providers on optimal treatment options for these commonly cooccurring conditions, especially among patients with CKD.

An important strength of the present study is the robust sample size captured in the EMR database. An additional strength is that the data evaluated spanned multiple recent years of patient information and laboratory data across multiple settings. Nevertheless, as with all retrospective analyses, the findings of this study should be considered within the context of certain limitations. First, the definition of metabolic acidosis used may not capture the true prevalence. For example, data pertaining to $\mathrm{pH}$ and the concentration of carbon dioxide in the blood, which are necessary to distinguish metabolic acidosis from respiratory alkalosis, were unavailable. While low bicarbonate values were much more likely to indicate metabolic acidosis than respiratory alkalosis among patients with CKD, respiratory alkalosis could not be ruled out in this study, which may result in an overestimation of the prevalence of metabolic acidosis. Additionally, accuracy of serum bicarbonate laboratory values depends on blood collection techniques. When a sample is exposed to air, it can result in carbon dioxide loss and reduced bicarbonate; the presence of fibrin clots in a sample of inadequate sample volume can lead to falsely low bicarbonate values. Second, it is possible that this study captured type IV renal tubular acidosis, which can occur in patients with diabetes and contribute to the progression of hyperkalemia. Inclusion of type IV renal tubular acidosis would also result in an overestimation of the prevalence reported in this study. However, since type IV renal tubular acidosis is relatively uncommon, we anticipate that the impact on including this would be minimal. Third, while the robust number of patients analyzed may adequately represent patients in Louisiana, it may not be generalizable to the entire population across all census regions in the US. To overcome this limitation, we age and gender standardized the prevalence to the US population of patients with CKD and hyperkalemia and found similar results. Lastly, similar to any EMR database, the EMR databases used in this study (i.e., Tulane Medical Center and Ochsner Health System) do not capture out-of-network healthcare encounters; however, Tulane Medical Center and Ochsner Health System are among the largest health systems in Louisiana and the coverage of the patient encounters is considered to be robust.

\section{CONCLUSION}

Metabolic acidosis was common among patients with CKD stage 3-5 and hyperkalemia, as the kidney's ability to maintain electrolyte and acid-balance is compromised. However, the prevalence of metabolic acidosis in this patient population varied based on the criteria used to define metabolic acidosis and hyperkalemia.

\section{ACKNOWLEDGEMENTS}

The research reported in this article was conducted in partnership with Research Action for Health Network (REACHnet), funded by the Patient Centered Outcomes Research Institute ${ }^{\circledR}$ (PCORI Award RI-CRN-2020-008). REACHnet is a partner network in PCORnet ${ }^{\circledR}$, the National Patient- Centered Clinical Research Network, which was developed with funding from PCORI $^{\circledR}$. The content of this article is solely the responsibility of the author(s) and does not necessarily represent the views of other organizations participating in, collaborating with, or funding REACHnet or PCORnet ${ }^{\circledR}$, or of PCORI ${ }^{\circledR}$. 
The authors acknowledge the participation of REACHnet partner health systems: Tulane Medical Center and Ochsner Medical Center in this project.

Funding. Sponsorship for this study and Journal's Rapid Service and Open Access fees were funded by AstraZeneca.

Editorial Assistance. Editorial assistance in the preparation of this article was provided by Dr. Gloria DeWalt, an employee of Analysis Group. Support for this assistance was funded by AstraZeneca.

Authorship. All named authors meet the International Committee of Medical Journal Editors (ICMJE) criteria for authorship for this article, take responsibility for the integrity of the work as a whole, and have given their approval for this version to be published.

Authors' Contributions. All authors contributed to the study conception and design, data collection, interpretation, manuscript compositon and editing. All authors read and approved the final manuscript.

Prior Presentation. A synopsis of this study was accepted for poster presentation at the National Kidney Foundation (NKF) Spring Clinical Meetings 2020, March 25-29, virtual live conference previously scheduled in New Orleans, Louisiana.

Disclosures. Erin E. Cook, Fan Mu, Keith A. Betts, Lei Yin, and Eric Q. Wu are employees of Analysis Group which received payment from AstraZeneca for the conduct of this analysis; Jill Davis. Rubeen Israni, and Deborah Anzalone are former employees of AstraZeneca; Vivian Fonseca receives research support through Tulane via grants from Bayer, Boehringer Ingelheim, and Gilead Sciences, Inc.; honoraria for consulting and lectures from Takeda, Novo Nordisk, Sanofi-Aventis, Eli Lilly and Company, Abbott, AstraZeneca, Intarcia Therapeutics, Inc., and Asahi Kasei Pharma; has stock options in Microbiome Technologies, Insulin Algorithms, and BRAVO4Health; and has stock in Amgen.
Harold Szerlip and Gabriel I. Uwaifo have nothing to disclose.

Compliance with Ethics Guidelines. This study was approved by the New England Independent Review Board on June 25, 2018. This study was performed in accordance with the Helsinki Declaration of 1964, and its later amendments.

Data Availability. The datasets generated during and/or analyzed during the current study are not publicly available due to partnership agreement with REACHnet.

Open Access. This article is licensed under a Creative Commons Attribution-NonCommercial 4.0 International License, which permits any non-commercial use, sharing, adaptation, distribution and reproduction in any medium or format, as long as you give appropriate credit to the original author(s) and the source, provide a link to the Creative Commons licence, and indicate if changes were made. The images or other third party material in this article are included in the article's Creative Commons licence, unless indicated otherwise in a credit line to the material. If material is not included in the article's Creative Commons licence and your intended use is not permitted by statutory regulation or exceeds the permitted use, you will need to obtain permission directly from the copyright holder. To view a copy of this licence, visit http://creativecommons.org/licenses/by$\mathrm{nc} / 4.0 /$.

\section{REFERENCES}

1. Raphael KL. Metabolic acidosis in CKD: core curriculum 2019. Am J Kidney Dis. 2019;74(2):263-75.

2. Chen W, Abramowitz MK. Metabolic acidosis and the progression of chronic kidney disease. BMC Nephrol. 2014;15:55.

3. National Kidney Foundation. KDIGO 2012 clinical practice guideline for the evaluation and management of chronic kidney disease. 2013. https:// kdigo.org/wp-content/uploads/2017/02/KDIGO_ 2012_CKD_GL.pdf. Accessed 2 Apr 2020 
4. Shah SN, Abramowitz M, Hostetter TH, Melamed ML. Serum bicarbonate levels and the progression of kidney disease: a cohort study. Am J Kidney Dis. 2009;54(2):270-7.

5. Raphael KL. Metabolic acidosis and subclinical metabolic acidosis in CKD. J Am Soc Nephrol. 2018;29(2):376-82.

6. Chen W, Abramowitz MK. Epidemiology of acid-base derangements in CKD. Adv Chronic Kidney Dis. $2017 ; 24(5): 280-8$.

7. Lim S. Metabolic acidosis. Acta Med Indones. 2007;39(3):145-50.

8. Betts KA, Woolley JM, Mu F, McDonald E, Tang W, $\mathrm{Wu}$ EQ. The prevalence of hyperkalemia in the United States. Curr Med Res Opin. 2018;34(6): 971-8.

9. Mu F, Betts KA, Woolley JM, Dua A, Wang Y, Zhong $\mathrm{J}$, et al. Prevalence and economic burden of hyperkalemia in the United States medicare population. Curr Med Res Opin. 2020;36:1333-1341.

10. Luo J, Brunelli SM, Jensen DE, Yang A. Association between serum potassium and outcomes in patients with reduced kidney function. Clin J Am Soc Nephrol. 2016;11(1):90-100.

11. Rossignol $P$, Legrand $M$, Kosiborod M, Hollenberg SM, Peacock WF, Emmett M, et al. Emergency management of severe hyperkalemia: guideline for best practice and opportunities for the future. Pharmacol Res. 2016;113(Pt A):585-91.

12. Harris AN, Grimm PR, Lee HW, Delpire E, Fang L, Verlander JW, et al. Mechanism of hyperkalemiainduced metabolic acidosis. J Am Soc Nephrol. 2018;29(5):1411-25.

13. Lehnhardt A, Kemper MJ. Pathogenesis, diagnosis and management of hyperkalemia. Pediatr Nephrol. 2011;26(3):377-84.

14. Batlle D, Arruda J. Hyperkalemic forms of renal tubular acidosis: clinical and pathophysiological aspects. Adv Chronic Kidney Dis. 2018;25(4): 321-33.

15. Karet FE. Mechanisms in hyperkalemic renal tubular acidosis. J Am Soc Nephrol. 2009;20(2):251-4.

16. Dobre M, Yang W, Chen J, Drawz P, Hamm LL, Horwitz E, et al. Association of serum bicarbonate with risk of renal and cardiovascular outcomes in CKD: a report from the chronic renal insufficiency cohort (CRIC) study. Am J Kidney Dis. 2013;62(4): 670-8.
17. Kraut JA, Madias NE. Consequences and therapy of the metabolic acidosis of chronic kidney disease. Pediatr Nephrol. 2011;26(1):19-28.

18. de Brito-Ashurst I, Varagunam M, Raftery MJ, Yaqoob MM. Bicarbonate supplementation slows progression of CKD and improves nutritional status. J Am Soc Nephrol. 2009;20(9):2075-84.

19. Mahajan A, Simoni J, Sheather SJ, Broglio KR, Rajab $\mathrm{MH}$, Wesson DE. Daily oral sodium bicarbonate preserves glomerular filtration rate by slowing its decline in early hypertensive nephropathy. Kidney Int. 2010;78(3):303-9.

20. Goraya N, Simoni J, Jo C, Wesson DE. Dietary acid reduction with fruits and vegetables or bicarbonate attenuates kidney injury in patients with a moderately reduced glomerular filtration rate due to hypertensive nephropathy. Kidney Int. 2012;81(1): 86-93.

21. Di Iorio BR, Bellasi A, Raphael KL, Santoro D, Aucella F, Garofano L, et al. Treatment of metabolic acidosis with sodium bicarbonate delays progression of chronic kidney disease: the UBI study. J Nephrol. 2019;32(6):989-1001.

22. Goraya N, Wesson DE. Management of the metabolic acidosis of chronic kidney disease. Adv Chronic Kidney Dis. 2017;24(5):298-304.

23. Menon V, Tighiouart H, Vaughn NS, Beck GJ, Kusek JW, Collins AJ, et al. Serum bicarbonate and longterm outcomes in CKD. Am J Kidney Dis. 2010;56(5):907-14.

24. Navaneethan SD, Schold JD, Arrigain S, Jolly SE, Wehbe E, Raina R, et al. Serum bicarbonate and mortality in stage 3 and stage 4 chronic kidney disease. Clin J Am Soc Nephrol. 2011;6(10): 2395-402.

25. Caravaca-Fontan F, Diaz-Campillejo R, Valladares J, Lopez Arnaldo C, Barroso S, Luna E, et al. Successful correction of metabolic acidosis is difficult to achieve in chronic kidney disease. Nefrologia. 2019;40:328-35.

26. KDIGO clinical practice guideline for the evaluation and management of chronic kidney disease. Kidney Int Suppl. 2013;3(1):136-50. https://kdigo. org/wp-content/uploads/2017/02/KDIGO_2012_ CKD_GL.pdf.

27. Kraut JA, Kurtz I. Use of base in the treatment of acute severe organic acidosis by nephrologists and critical care physicians: results of an online survey. Clin Exp Nephrol. 2006;10(2):111-7. 
28. Kovesdy CP. Metabolic acidosis and kidney disease: does bicarbonate therapy slow the progression of CKD? Nephrol Dial Transplant. 2012;27(8):3056-62.

29. Kraut JA, Madias NE. Metabolic acidosis of CKD: an update. Am J Kidney Dis. 2016;67(2):307-17.

30. Eustace JA, Astor B, Muntner PM, Ikizler TA, Coresh J. Prevalence of acidosis and inflammation and their association with low serum albumin in chronic kidney disease. Kidney Int. 2004;65(3): 1031-40.

31. Moranne O, Froissart M, Rossert J, Gauci C, Boffa JJ, Haymann JP, et al. Timing of onset of CKD-related metabolic complications. J Am Soc Nephrol. 2009;20(1):164-71.

32. De Nicola L, Di Lullo L, Paoletti E, Cupisti A, Bianchi S. Chronic hyperkalemia in non-dialysis CKD: controversial issues in nephrology practice. J Nephrol. 2018;31(5):653-64.

33. DuBose TD Jr. Molecular and pathophysiologic mechanisms of hyperkalemic metabolic acidosis.
Trans Am Clin Climatol Assoc. 2000;111:122-33 (Discussion 33-4).

34. Dunn JD, Benton WW, Orozco-Torrentera E, Adamson RT. The burden of hyperkalemia in patients with cardiovascular and renal disease. Am J Manag Care. 2015;21(15 Suppl):s307-15.

35. Gaggl M, Sliber C, Sunder-Plassmann G. Effect of oral alkali supplementation on progression of chronic kidney disease. Curr Hypertens Rev. 2014;10(2):112-20.

36. Mahoney BA, Smith WA, Lo DS, Tsoi K, Tonelli M, Clase CM. Emergency interventions for hyperkalaemia. Cochrane Database Syst Rev. 2005;(2): CD003235

37. Spinowitz BS, Fishbane S, Pergola PE, Roger SD, Lerma EV, Butler J, et al. Sodium zirconium cyclosilicate among individuals with hyperkalemia: a 12-month phase 3 study. Clin J Am Soc Nephrol. 2019;14(6):798-809. 